\title{
Waste Management System in Karachi as an Environmental and Health Hazard
}

\author{
Musarrat Shamshir* \\ Associate Professor, Greenwich University \\ DK-10, $38^{\text {th }}$ Street, Darakshan, Phase VI, Defence Housing Authority, Karachi, 75500, Pakistan \\ Sehrish Butt \\ Research Scholar, Greenwich University \\ DK-10, $38^{\text {th }}$ Street, Darakshan, Phase VI, Defence Housing Authority, Karachi, 75500, Pakistan \\ S. Khurram Khan Alwi \\ Associate Professor, Greenwich University \\ DK-10, $38^{\text {th }}$ Street, Darakshan, Phase VI, Defence Housing Authority, Karachi, 75500, Pakistan
}

\begin{abstract}
Present research is an attempt to describe the problem of waste management of Karachi and its possible impact as a health hazardous issue in the city. The study mainly focuses on the issues of solid waste management in the sampled areas of Defence Housing Authority (DHA) Karachi and Cantonment Board Clifton (CBC). A poll result shows that the sewerage management is comparatively better than the other areas. However, additional and adequate waste management measures to overcome some problems faced in solid as well as effluent disposal. Conditions in the waste management system can be improved if all the concerned departments worked on a policy of mutual co-operation and co-ordination. This will not only ensure healthier and efficient system but also provide incentive for improvement to areas other than the sampled area.
\end{abstract}

Keywords: Solid Waste Management, Clifton Cantonment Board, Environmental Decency, General Welfare.

DOI: 10.7176/PPAR/9-4-07

Publication date: April $30^{\text {th }} 2019$

\section{Introduction}

Waste management plays a very significant role in town planning and the general welfare of the denizens. It is as much important as other amenities required for good civic living and environmental decency. Karachi being the largest city of Pakistan faces serious waste management problem and needs a solution. There is a growing problem of waste management faced by developing countries, especially in urban areas of Pakistan. Karachi as an example is the biggest city of Pakistan having a bustling population of about 24 million. It is a cosmopolitan city. The rate of generation and composition of solid waste has changed in recent years due to booming populations, infrastructural development, lifestyle changes, and increasing trends of urbanization (Paracha,2014). Karachi is the greatest urban center of Pakistan and the second largest Muslim city in the world. It is reported about 12,000 tons of solid waste per day is generated there, $40 \%$ of which is scattered on the city streets. The major problems of any developing city include the handling of solid waste. Nowadays a massive challenge for urban areas is efficient solid waste management (Abas \& Wee, 2014). The trend of urbanization has been rapidly increasing in Pakistan since the 1970s, with the majority of the population shifting to the urban centers of the country from the rural regions, in order to seek better employment opportunities (Sharif \& Raza, 2016). Lack of adequate management of solid waste poses serious hazards in spreading infectious diseases and environmental pollution. Located on the southern coast, it is considered as the business hub of Pakistan.

This study focuses on the important issue of solid management which challenges the waste management authorities. A survey shows that citizens were not satisfied with the prevailing strategies employed by municipal solid waste authorities. In a nutshell, solid waste management is a process by which a city is kept clean on a regular basis and which effectively handles waste collection and disposal, sewerages, water treatment, recycling, and health and hygiene issues. During the monsoon season, blocked sewerage systems become problematic for municipalities.

It was noted that the people are very much concerned about the ill-equipped city and poorly conducted operation of the municipalities to collect and dispose off waste properly. It was also noted that the municipalities suffered from poor funding and lack of dedication for the task. Apart from this the most denizens lack sense of civic living and are major contributories to this malaise as a result of which this serious problem almost seems to have gone out of control. Obviously, this drastic situation calls for immediate attention to improve the situation through effective and consolidated practical means. There is also need for educating people on how to minimize waste and to recycle it for some useful purpose. 


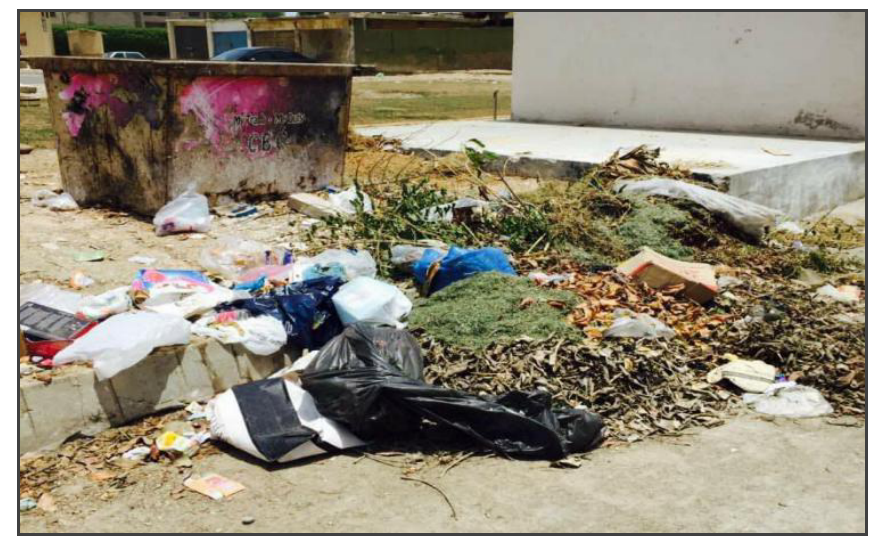

Lack of Waste Management system in DHA

Karachi is governed by a city district government and is split into six districts with further divisions into 18 sub-districts or tehsils. Every tehsil is administratively separated into 178 union councils which manage solid waste. Under City District Government Karachi (CDGK), there are two cantonment boards which include the Karachi Metropolitan Corporation (KMC) and District Municipal Corporation (DMC) other than the solid waste management system in Karachi. If these municipalities do not manage solid waste properly, it creates damaging environmental and health impacts. Apart from this, there are also Cantonments managing waste disposals in their respective areas. Unfortunately, lack of co-operation and co-ordination among these authorities is also a major factor affecting the due process of city waste management in a proper and beneficial manner. The types of municipal wastes posing environmental and health hazards due to lack of proper disposal are observed to be: household waste, office waste, street litter, synthetic waste, over-flowing manholes, blocked or broken storage system etc.

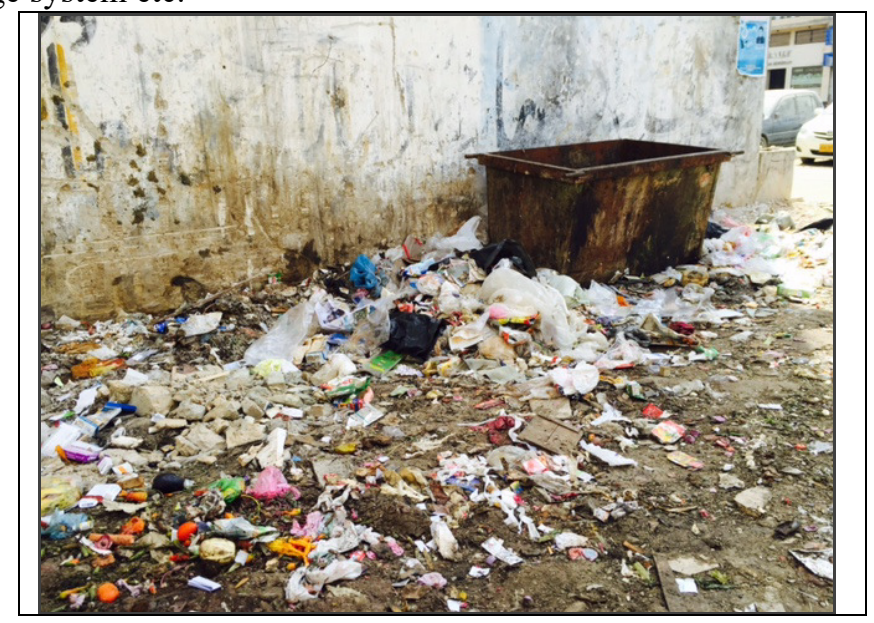

\section{Rotten Garbage at DHA Phase 5 Commercial Area}

This is high time that the waste management is thoroughly revamped and upgraded to meet with the growing population and need for effective waste disposal. It is not desirable that about $60 \%$ of the local waste is used as a landfill or a part of it be burnt on the streets. This trend must be done away with and proper strategy should be adopted to put all this waste into useful activity. For example, in UAE, the wet waste is collected by suction pump trucks on daily basis and this waste sewerage is recycled to produce water for the purpose of horticulture or agriculture. It is bad practice to run down most of the sewerage effluent into the sea. Doing this has already destroyed our beaches and turned them into filthy places. In developed countries, the waste management system aims at connecting and disposing off all kinds of waste for beneficial use. The waste is collected, segregated and its each component is recycled. Many paper, plastic and glass items are recycled and they not only provide a source of employment and peculiarly benefits but they also contribute to the national exchequer and preservation of our forests and environment. 

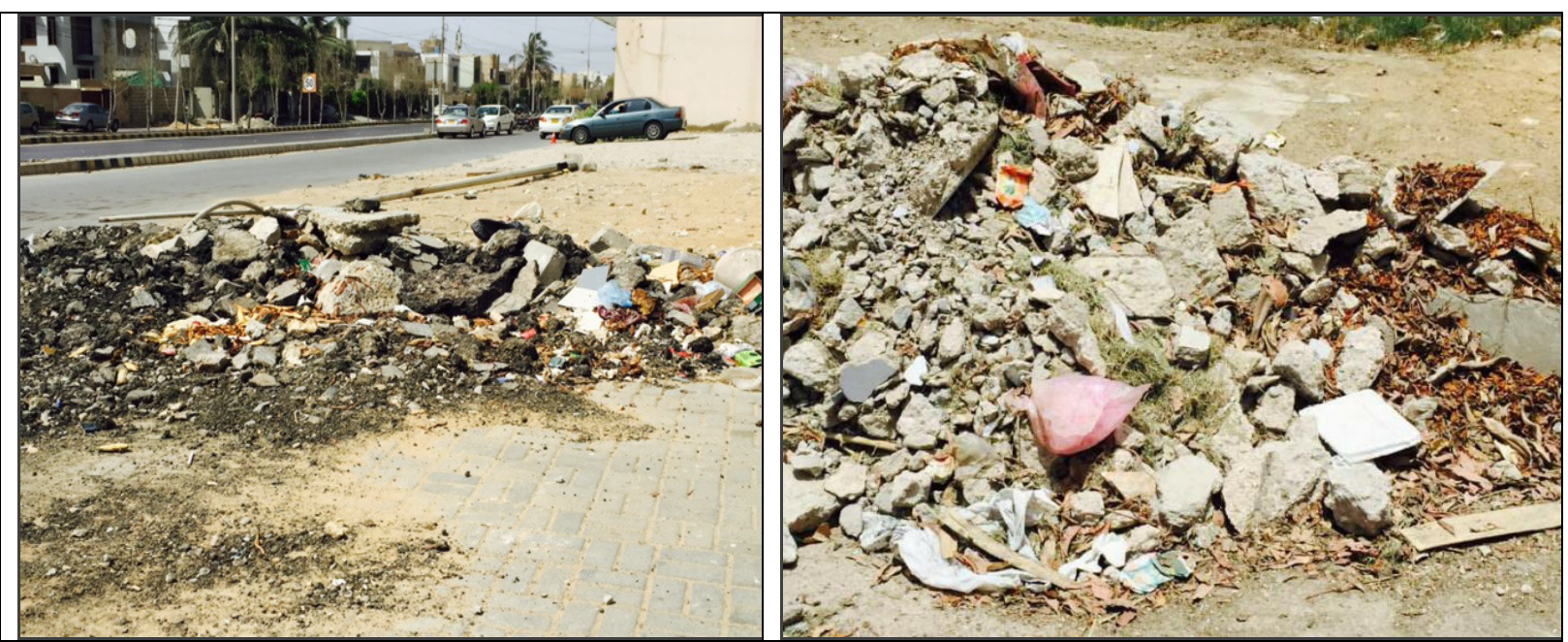

Heap of Debris and Construction Waste at Various Sites of Defence

Unfortunately, the larger governance construct of Karachi suffers from a state of crisis, uncertainty, disarray and lack of trust, co-operation and co-ordination among the service providers. It is a pity that the waste management sector of Karachi is taken casually and is not properly documented and regulated nor there is no updated data available about it. As regards funding the federal government must advance adequate funds to the local government enabling it to devise and implement better ways to improve the current situation and bring it at par with any other civilized and organized cities. However, this is only possible when the funds are fully employed for the purpose and not fizzled away due to corruption. A rigid policy is required to control this situation judiciously and effectively in the common interest of public and the nation itself. Suitable modern machinery for collecting and disposing city waste is urgent need of the day. It is also necessary to keep this machinery fully maintained and in order all the time. It should also be checked that the menace of ghost employee janitors and other staff is eliminated. Unless all these steps are taken the dream of a clean city like Karachi will not come true. All this is needed by the concerned municipalities and the public dedicate themselves with honest conviction to this issue for the purpose of ensuring a neater, happier and healthier public life. Objective of the present study is to identify methods to improve the waste management in the city to ensure health living of the people and to educate people to dispose of waste properly.

\section{Literature Review}

Yasmin \& Rehman (2017) conducted a study of waste management systems in the capital of Bangladesh poses problems in waste collection and disposal and recommended express need of improvement in this sector. According to World Health Organization (2014) termed Dhaka as one of the most polluted cities. The total waste collection rate in major cities of Bangladesh such as Dhaka is only $37 \%$. When waste is not properly collected, it will be illegally disposed off and this will pose serious environmental and health hazards to the Bangladeshis. According to Hasan \& Chowdhury (2006), un collected waste is a huge issue in Bangladesh. About 14-17 \% waste is collected and the waste that is uncollected in Bangladesh is managed informally and illegally; usually dumped in nearby drains, ponds and even in other streets and localities (Hasan \& Chowdhury, 2006; Matter \& Zurbrügg, 2013). Uncollected waste may pollute environment, scattered garbage can cause air pollution and drain clogging, water pollution may water borne disease and may cause serious health hazards. The importance of recycling of solid waste has been highlighted by Linzer \& Lange (2013). Households can play a key role in separating the recycling material from the kitchen waste and can reduce the significant amount of solid waste. Another possible solution of managing kitchen waste is the production of organic compost, thereby reducing the amount of waste material left for managing. Preparing the compost out of solid waste is a most appropriate solution of developing economies, which on one hand is low technology and low cost option and on the other hand protects the environment (Haria et al., 2015). In this context combined efforts at both public and private level may have a significant contribution and public-private ventures make develop a sense of awareness through awareness programs Bhuiyan, 2019).

\section{Research Methodology}

This study is mainly based on qualitative phenomenological and quantitative survey research method. Instruments of research used are; interviews and questionnaire. For this purpose, interview with the middle management were conducted; a questionnaire with the close-ended questions was developed for interviewing the concerned department, in this case the Cantonment Board Clifton. The population size for this survey was the residents of DHA Karachi. A sample 100 males and 120 females of different age group were surveyed to find the 
real reasons of ineffective waste management system. The participants were selected from different areas of DHA to have diverse data set regarding waste management system in their respective areas. Empirical evidence was drawn in the light of questions posed to the concerned functionary respondent of the CBC, recorded and transcribed for further compilation assessment analysis and evaluation. Due to very broad aspect of the study and dearth of time, the study was directed to Defence Authority Karachi on the basis of convenience sampling methods. The statistical analysis was made using SPSS.

\subsection{Hypothesis 1}

Hazards posed to health and environment due to ineffective waste management system.

\subsection{Hypothesis 2}

Problems faced to waste management system due to lack of organized planning and operation.

\section{Analysis and Findings}

Empirical data collected through interview from $\mathrm{CBC}$ suggested that the collection and disposal of the entire waste found in DHA's territorial jurisdiction was the sole responsibility of CBC for which a separate wing under the name and style of Sanitation Wing is functioning. The collected data shows that 985 personnel are engaged for this specific task; deployed in two shifts. Machinery is employed to clear the garbage on daily basis through 130 compactors, tractors, trucks, dumpers, scoops and blade trolleys. About $25-30$ supervisors are deputed to look after the job. However, there is no proper method for disposal of solid waste and the same is transported to a remote residential town; Surjani and dumped and leveled there for landfill. The real problem of waste littering occurs in commercial areas of Defence where the shops are opened till late night and visitors' litter all around without bothering to put rubbish into the garbage bins placed by $\mathrm{CBC}$. The fluid waste is lead directly into the sea and poses great threat to the safety of the environment through pollution. Choked gutters and sewerage pipelines are either handled manually by janitors or in serious cases evacuation pumps are used.

Lack of civil sense by the public and lack of co-ordination and co-operation between CBC and other concerned metropolitan authorities is the root cause of any short-coming encountered in fool proof collection and disposal of waste. For example, the beaches of Clifton suffer badly from waste pollution yet CBC absolves itself from the responsibility to rectify the problem stating that the beaches do not fall into their territorial jurisdiction and that it is the job of Coast-Guards and Pakistan Maritime Agency (PMA).

Table 1. Hazards posed to health and environment due to ineffective waste management system.

\begin{tabular}{lccc} 
One sample test & Sample size & Mean difference & $\boldsymbol{t}$-values \\
\hline Pollution & 250 & 1.82 & 24.628 \\
Garbage Collection Issue & 250 & 1.56 & 20.405 \\
Sanitation Issue & 250 & 1.76 & 15.616 \\
\hline
\end{tabular}

Results on table 1 show that one of the health hazards posed due to environment degradation is due to ineffective waste management system. In case of garbage collection and sanitation problem the result shows significant values conclude that condition in the area are not up to the mark and needs considerable improvement.

Table2. Problems faced to waste management system due to lack of organized planning and operation.

\begin{tabular}{lccc}
\hline One-sample test & Sample size & Mean difference & t-statistics \\
\hline Complaint system & 250 & 1.74 & 18.523 \\
Awareness program & 250 & 1.98 & 29.577 \\
Corruption & 250 & 2.38 & 24.158 \\
\hline
\end{tabular}

Results in table 2 show significant values regarding awareness programs conducted; the complaint system and possible corruption in the system. Hence, we conclude that problems faced to waste management system are due to lack of planning, co-ordination and co-operation. More awareness programs to improve the waste management system are required. The complaint system must be improved and the whole system must completely corruption free.

\section{Conclusion and Discussion}

Out of 14,000 ton per day of solid waste produced in Karachi, the Clifton Cantonment Board handles a meager 400 tons waste per day. Over all Cantonment exercises good control over waste related problems which may help ward off disease and keep the environment clean. To do this, Clifton Cantonment employs a team of about 984 personnel quipped with solid waste gathering, lifting and transportation vehicles and machinery. However, it will soon have to take additional measures to tackle more and more waste produced by the rapid expansion of 
DHA and population growth in the area. Unless, advanced measures in this regard are not planned and taken it might pose difficulties to the concerned authorities to manage waste gathering and disposal adequately in rapidly spreading out of construction and migration of more and more people here from areas beyond cantonment. As compared to other areas of Karachi, DHA waste management is quite better and efficient because the overall conditions prevailing here are comparatively much better. In spite of all this, the CBC has yet to take additional and adequate waste management measures to overcome some problems faced in solid as well as effluent disposal. Moreover, the authorities must also start public awareness programs in this respect and install proper sign boards at different places to highlight educational direction to the public about the significance of waste disposal by placing more bins at various points. Lack of coordination among the departments and their negligence is destroying the scenic beauty of beaches and adding to the degradation of environment.

\section{Recommendations}

It is imperative that all concerned departments and authorities join hands together to improve the waste management situation through friendly co-operation and co-ordination and honest conviction to make this area of the city as well the whole city itself into a model paradigm. Lack of funding must be overcome and whatever funds are available must be spent for right job. Attention should be directed to recycling of solid waste and putting it to beneficial use. Awareness campaign must be launched to advance better sense of civil living among people for creating a healthier environment in their own benefit. City must take alternative measures to disposeoff sewage effluent in some proper ways such as filtration and marine resources rather than dump it into the sea beaches to ensure pollution-free environment and beauty of beaches.

\section{References}

Bhuiyan SH. (2009). A Crisis in Governance: Sustainable Urban Solid Waste Management in Bangladesh. Nepalese Journal of Public Policy and Governance, 24 (1), 63-80.

Cantonment Board Clifton. (2015-2016). http://cbc.gov.pk/home/engineering-branch/solid-waste-management/. Retrieved from http://cbc.gov.pk.

Harir AI, Kasim R, Ishiyaku B. (2015). Exploring the Resource Recovery Potentials of Municipal Solid Waste: A Review of Solid Wastes Composting in Developing Countries. International Journal of Scientific and Research Publications, 5 (8).

Hasan GMJ \& Chowdhury AI. (2006). Municipal solid waste management and environmental hazards on Bangladesh. Asian Journal of Water, Environment and Pollution, 3 (1), 39-48.

Linzner R and Lange U. (2013). Role and size of informal sector in waste management - a review. Proceedings of the ICE - Waste and Resource Management, 166 (2), 69-83.

Sabir, W., Waheed, S. N., Afzal, A., Umer, S. M., \& Rehman, S. (2016). A Study of Solid Waste Management in Karachi City. Journal of Education \& Social Sciences , 4(2), 151-163..

The Official Portal of UAE Government. (2017). Clean Water And Sanitation. UAE: Government.ua.

Waste Incinerator : Medical, Hazardous, Industrial Waste, Animal Carcass Incineration. (2015, October 22). The Waste Management System of Pakistan ..

Yasmin, S., \& Rahman, M. I. (2017). A Review of Solid Waste Management Practice in Dhaka City, Bangladesh. International Journal of Environmental Protection and Policy , 5(2), 19-25. 
$50 \%$ of the daily generated waste

remains uncollected in the city and disposed at official dump sites. Only $14-17 \%$ of the total municipal budget is used for solid waste management which is approximately 0.5 USD per capita per year. As a result, the uncollected waste is primarily dumped illegally in the neighborhood's streets, wastewater drains, ponds, lakes etc. or managed informally [39]. Matter A, Dietschi M, Zurbrügg C. Improving the informal recycling sector through segregation of waste in the household-The case of Dhaka Bangladesh. Habitat International, 2013; 38: 150-156.

Uncollected waste has been recognized as the root of inferior environment such as scattered garbage, offensive odor, drain clogging, water pollution and mosquitoes

47.

50 .

Households can play a

predominant role, as they have the capacity to substantially reduce the amounts of unwanted waste at household level by segregating clean materials which have a recyclable value such as plastic or paper - instead of mixing them with other fractions such as kitchen waste, and thus diminishing their potential recycling value [45]. 